\title{
MODELING SHORT-RANGE BALLISTIC MISSILE DEFENSE AND ISRAEL'S IRON DOME SYSTEM
}

\author{
MICHAEL J. ARMSTRONG \\ Goodman School of Business, Brock University, St. Catharines, ON, L2S 3A1, Canada, \\ michael.armstrong@brocku.ca
}

This paper develops a model of short-range ballistic missile defense and uses it to study the performance of Israel's Iron Dome system. The deterministic base model allows for inaccurate missiles, unsuccessful interceptions, and civil defense. Model enhancements consider the trade-offs in attacking the interception system, the difficulties faced by militants in assembling large salvos, and the effects of imperfect missile classification by the defender. A stochastic model is also developed. Analysis shows that system performance can be highly sensitive to the missile salvo size, and that systems with higher interception rates are more "fragile" when overloaded. The model is calibrated using publically available data about Iron Dome's use during Operation Pillar of Defense in November 2012. If the systems performed as claimed, they saved Israel an estimated 1778 casualties and $\$ 80$ million in property damage, and thereby made preemptive strikes on Gaza about 8 times less valuable to Israel. Gaza militants could have inflicted far more damage by grouping their rockets into large salvos, but this may have been difficult given Israel's suppression efforts. Counter-battery fire by the militants is unlikely to be worthwhile unless they can obtain much more accurate missiles.

Subject classifications: Warfare models: tactical ballistic missiles, counterinsurgency, Hamas-Israel conflict; Defense systems: ballistic missile defense, civil defense.

Area of review: Military and Homeland Security

\section{Introduction}

Ballistic missile defense (BMD) has been a topic of interest for operations researchers for over 50 years (Matlin, 1970). This research has mostly focused on strategic defense against nuclear-armed intercontinental ballistic missiles (ICBMs); thankfully these weapons have never seen hostile action. Some studies have instead examined theater defense against medium-range ballistic missiles (e.g., Brown et al, 2005). Systems of this type, such as the Patriot interceptor missile, have been deployed in several countries, and a few have participated in actual combat (Shapir, 2013a; Wilkening, 1999).

The role in which BMD has seen the most combat, but the least research, is tactical defense against short-range missiles. Israel's Iron Dome "counter-rocket, artillery, and mortar" system entered operational service in March 2011, and in the following month claimed its first interception of an enemy rocket (Shapir, 2013b). By early 2012, 4 batteries had been deployed; later that year these became heavily engaged during Operation Pillar of Defense (OPOD), and were credited with 421 rocket interceptions over 8 days (IDF, 2012a).

Iron Dome's performance has attracted an unusual amount of public attention. Live combat videos have appeared on the internet (Rafael, 2014), recruits for the Israel Defense Forces (IDF) consider it prestigious to be assigned to the batteries (Shapir, 2013b), and one Israeli town asked the courts to order a battery into their region (Paraszczuk, 2011). This civilian interest is not surprising, given the high frequency of rocket attacks in Israel. Between 2005 and 2013, Gaza militants fired 8977 rockets towards southern Israel (ISA, 2013b), and Lebanese militants launched thousands more. In 2012, rockets were the cause of $78 \%$ of the country's total casualties due to terrorist attacks (ISA, 2012). 
Iron Dome has also attracted controversy regarding how well it actually stops incoming missiles; some commentators have been very skeptical (Broad, 2013; Pedatzur, 2013) while others have been supportive (Kober, 2013; Rubin, 2013; Shapir, 2013a). Other writers have questioned whether the system encourages or hinders peace in the Middle East, and whether it offers any lessons for BMD efforts in other countries and at other levels (Kober, 2013; Selinger, 2013; Shapir, 2013b). There are concerns as well in Israel and the USA regarding the high costs of developing the technology, building the batteries, and replenishing the ammunition (Harel and Cohen, 2014; BBC, 2012). Given this interest and debate, a better understanding of Iron Dome in particular and short-range BMD in general would be valuable.

This paper develops a model of short-range BMD and uses it to analyze the performance of the Iron Dome system during OPOD. The work is related to several topics in military operations research, including BMD, naval missile warfare, and counter-terrorism.

The most obvious connection is to missile warfare at the theater and strategic levels. Brown et al (2005) is an example of theater BMD research, while studies of strategic BMD include Soland (1987), and Burr, Falk, and Karr (1985); see Matlin (1970) or Eckler and Burr (1972) for reviews of earlier work. This research tends to focus on the optimization of each side's missile allocation problem (MAP): i.e., allocating attacking ICBMs to target cities to maximize the damage inflicted, or allocating defending interceptors to incoming missiles to minimize the damage suffered.

Although short-range BMD shares much of the same physics and terminology as strategic and theater BMD, its decision context can be quite different. MAP tends to focuses on detailed planning of one-time attacks, whereas the work herein considers on-going operations over prolonged periods. Iron Dome, for example, has been dealing with periodic rocket attacks for several years. MAP is also less relevant for short-range missiles because of their small warheads and low accuracy relative to the large area targets. Detailed allocation of missiles to targets would be a secondary concern for the attacker, and may not even be practical for a mobile or insurgent force with only partial control of its surroundings. The attacker may simply want to land as many missiles as possible in the target area. Similarly, the defender must deal with missiles that have flight times measured in seconds, coming from launchers in unknown locations, against area targets; thus its interception decisions change as well.

The study by Wilkening (1999) is closer in style to the work herein. Instead of optimizing MAP, he constructs a simple aggregate model for national and theater BMD. His objective is to determine how many interceptors would be required to provide a given probability that all the incoming missiles are intercepted. By contrast, the modeling herein estimates the mean losses due to non-intercepted missiles. As well, his calculations assume that every missile is engaged by at least one interceptor, whereas this paper allows overloading of the interception system by large salvos.

This study is also similar in style to the salvo models of naval missile combat of Hughes (1995) and Armstrong $(2005,2014)$. In that context, the interplay between offensive missiles and defensive interceptions is central, and salvo size is a key parameter (Armstrong, 2007). However, that research considers cruise missiles fired at warships: multiple interception attempts are possible, hits on the target will reduce future interceptions, and a single salvo will often end the battle. Conversely, the models here represent ballistic missiles fired at urban targets: at most one interception attempt per missile is possible, hits do not reduce the interception ability, and the conflict could be prolonged.

Given the source of the attacks, the work herein also is related to counterinsurgency and counterterrorism. This area has seen much recent modeling research. Kress (2005), for example, models the number of casualties inflicted by a suicide bomber. Other studies include Arce, Kovenock, and Roberson (2012), Atkinson and Wein (2008), Enders and Sandler (2012), and Kaplan (2010). In particular, this work and that of Kaplan, Kress, and Szechtman (2010) both consider conflicts in which 
militants fire rockets at Israel. Their work models a ground offensive to attack the militants before they fire their rockets, whereas this study models air defenses that intercept the rockets after launch.

This paper begins by constructing a deterministic model in which the attacker's missiles may be inaccurate, the defender's interceptions may be unsuccessful, and missile damage can be mitigated by civil defense measures. It subsequently enhances the model to reflect imperfect knowledge of the missiles' trajectories, security efforts that discourage large salvos, and counterbattery fire against the interception system itself. The paper also develops a stochastic version of the base model.

Analysis shows that the system's performance is heavily influenced by the attacker's salvo size. Damage remains constant as long as the salvo remains smaller than the system's interception capacity, quickly increases as that capacity is exceeded, and then exhibits diminishing returns thereafter. This nonlinear behavior is more pronounced for systems with higher interception rates; that is, "better" systems are ironically more "fragile" when overloaded. Better interception systems also make other protective measures, such as civil defense and preemptive strikes, less valuable to the defender.

Further analysis shows that targeting the BMD system itself is increasingly worthwhile for attackers who possess more numerous and/or more accurate missiles. It also becomes more worthwhile as interception rates increase, except perhaps when those rates become extremely high. Despite the greater power of large salvos, they might not be used if the attacker risks having its missiles preemptively destroyed. If that risk is high enough, the attacker is better to fire missiles one at a time.

The model is calibrated with publically available data on the performance of Iron Dome during OPOD in November 2012. Some of those data are very approximate, but they illustrate the model's application and provide a sketch of the system's impact. During OPOD, militants in Gaza fired 1506 rockets towards Israeli towns (IDF, 2012a), causing 245 casualties and an estimated \$11 million of property damage. If the Iron Dome batteries intercepted rockets as well as the IDF claimed, then the model estimates they saved Israel 1778 civilian casualties and $\$ 80$ million of property damage. They also made it 8 times less valuable for the IDF to destroy the militants' rockets preemptively, and thus much less tempting for Israel to invade Gaza.

The militants could have overcome Iron Dome's impact by coordinating their attacks into larger salvos. For example, rough numerical work suggests that firing the rockets in salvos of about 50 at a time, rather than piecemeal, could have quintupled Israel's losses. But the militant's irregular forces could have found this difficult or even counter-productive, given Israel's efforts to locate and destroy rocket launchers. The calculations also suggest that firing rockets directly at the Iron Dome batteries is not currently worthwhile, but could become so if the militants obtain much more accurate missiles. If the batteries sometimes misclassify incoming rockets as accurate instead of inaccurate, or vice versa, this could explain some of the differences in reports regarding Iron Dome's success rate.

\section{Basic Model}

Consider a conflict between opponents Red and Blue, in which Red will fire short-range ballistic missiles at Blue targets. Red has an available stockpile of $A$ missiles to launch in salvos of $m \geq 1$ missiles each, for a total of $A / m$ salvos. Proportion $p_{m}$ of these missiles will strike targets unless intercepted, while proportion $1-p_{m}$ will miss. For convenience, the former missiles will be called "accurate" and the latter ones "inaccurate".

Blue can detect these missiles and determine their trajectories; it will ignore the inaccurate missiles and try to intercept the $m p_{m}$ accurate ones. It can attempt to intercept up to $n \geq 0$ missiles per salvo; only proportion $p_{n}$ of those interceptions will succeed, giving it an effective capacity of $n p_{n}$ 
successful interceptions. Because of the short flight times, Blue can attempt to intercept each missile no more than once. Blue cannot "shoot-look-shoot", though it could fire several anti-missile missiles together as a volley. This single-attempt assumption is similar that of Brown et al (2005), but is different from other BMD models such as Soland (1987) and Wilkening (1999). Aside from Tiah (2007), it also differs from most naval salvo model research, such as Hughes (1995) and Armstrong $(2005,2014)$.

Even if Blue has enough capacity to try to intercept every accurate missile, proportion $\left(1-p_{n}\right)$ of the interceptions will fail, allowing $m p_{m}\left(1-p_{n}\right)$ missiles to penetrate the defenses. The other $m p_{m} p_{n}$ missiles will be intercepted if Blue has sufficient effective capacity $n p_{n}$. Thus the number of Red missiles per salvo that hit Blue targets will be as follows.

$$
\text { Hits/salvo }=m p_{m}\left(1-p_{n}\right)+\left[m p_{m} p_{n}-n p_{n}\right]^{+}
$$

For example, suppose that $p_{m}=3 / 4$ of Red's missiles are accurate, and that Blue can attempt $n=6$ interceptions per salvo, of which $p_{n}=2 / 3$ succeed. If Red fires $m=4$ missiles, then 1 will be miss; Blue will engage the other 3 and succeed 2 times, leaving 1 missile to hit the target. If instead Red fires 12 missiles, then 3 will miss; Blue will engage 6 of the rest and succeed against 4, leaving 5 to hit.

Each hit will inflict nominal damage of value $v$ against a target. Damage may be measured in human casualties, material destruction, financial cost, etc. However, Blue may reduce this damage by taking advance measures to harden buildings, construct warning systems and shelters, and so forth. (This corresponds to "civil defense" in the BMD context, and "staying power" in the naval context.) Parameter $h \geq 1$ represents these hardening efforts, so that the effective damage per hit is reduced to $v / h$.

Blue's targets are assumed to cover large areas relative to the destructive power of the missiles, so that Red cannot run out of targets or risk "overkill". Example targets are towns full of buildings, and bases full of soldiers. The total damage is therefore proportional to the number of missiles that hit.

Combining the number of salvos fired, the number of hits per salvo, and the effective damage per hit, yields the following expression for the total loss inflicted on Blue targets by Red missiles.

$$
\text { Loss }=(A / m)\left\{m p_{m}\left(1-p_{n}\right)+\left[m p_{m} p_{n}-n p_{n}\right]^{+}\right\}(v / h)
$$

\section{Model Properties}

Equations 1 and 2 are heavily influenced by the size of Red's salvo relative to Blue's interception capacity. In particular, it is useful to distinguish between "small" and "large" salvos.

Salvos are "small" whenever Blue can attempt to intercept all of the accurate missiles; i.e., when $m p_{m} \leq n$. In this case, missiles hit targets only where the corresponding intercept attempt fails (i.e., the missiles "leak" through the defenses), and Equation 2 simplifies to Loss $=A p_{m}\left(1-p_{n}\right)(v / h)$.

Salvo sizes are "large" when there are more accurate missiles than Blue can attempt to intercept; i.e., $m p_{m}>n$. In this case, missiles that survive interception are joined by ones that outnumber the defense; they exceed the "price of admission". In the limit, Loss $\rightarrow A p_{m}(v / h)$ as $m \rightarrow \infty$.

Taking derivatives of Equation 2 (see appendix) confirms the following first-order influences. (a) For all salvo sizes, losses are increasing in missile stockpile $A$ and damage per hit $v$; and decreasing in target hardening $h$ and interception success rate $p_{n}$.

(b) For small salvos, losses are "slowly" increasing in missile accuracy rate $p_{m}$; and unaffected by salvo size $m$ or interception capacity $n$. 
(c) For large salvos, losses are "quickly" increasing in missile accuracy rate $p_{m}$ and salvo size $m$; and decreasing in interception capacity $n$.

Improving missile accuracy always increases losses, but the rate of increase depends on the salvo size. With small salvos $\partial$ Loss $/ \partial p_{m}=\left(1-p_{n}\right) A v / h$, while with large salvos $\partial$ Loss $/ \partial p_{m}=A v / h$. The $\left(1-p_{n}\right)$ term means that losses increase more slowly with small salvos, especially if most interceptions succeed.

Similarly, the impact of increasing salvo size depends on whether the salvos are (or become) large, as then $\partial \operatorname{Loss} / \partial m=p_{n}\left(n / \mathrm{m}^{2}\right)(A v / h)$. This expression is positive but decreasing, indicating that losses are concave-increasing in $m$; i.e., they increase but with diminishing returns. Thus the greatest increases occur around the transition from small to large salvos at $m=n / p_{m}$, while smaller increases occur with larger salvos. (No increases occur with small salvos.)

Some of the second-order influences are also worth noting; they can be found by taking the appropriate second partial derivatives of Equation 2. Blue's efforts to increase effective interception capacity $m p_{n}$ or target hardening $h$, or to reduce Red's stockpile $A$, accuracy $p_{m}$, damage value $v$, or salvo size $m$, are all "supplementary" to each other. That is, improvements in one make improvements in the others less valuable. By contrast, the interception capacity $n$ and success rate $p_{n}$ are "complimentary": increases in one make increases in the other more valuable.

\section{Israel's Iron Dome System}

\subsection{Background}

Israeli towns have been attacked periodically by rockets fired by militants in the Gaza Strip to the south and Lebanon to the north. For example, during the first 10 months of 2012 Israel reported 596 rockets launchings from Gaza (ISA, 2012). Most of these have been unguided short-range rockets such as the Grad and Qassam. Depending on the version, Grad artillery rockets carry 18 to $21 \mathrm{~kg}$ of explosive to a range of up to $32 \mathrm{~km}$ (FAS, 1999), while Qassam improvised rockets carry from 0.5 to $15 \mathrm{~kg}$ of explosive up to $17 \mathrm{~km}$ (Dullum, 2009).

Israel has been developing several interception systems to counter these attacks. The only one that has seen action so far is Iron Dome (Rafael, 2010). Each Iron Dome battery consists of a radar module, a command module, and 3 launchers; each launcher carries 20 Tamir interceptor missiles (Shapir, 2013b). The system developers faced a difficult task: “... design a rocket system that can identify a rocket launch, classify its type, calculate its trajectory, decide the level of the threat it poses, launch an interceptor missile at it, keep the interceptor locked onto the incoming rocket, and blow it out of the sky and all within a minimum of 15 seconds and a maximum time of 40 seconds, depending on the distance from the launch source" (Mizroch, 2012).

\subsection{Operation Pillar of Defense}

From 14 to 21 November 2012, the IDF launched a series of air strikes against militant targets in Gaza as part of OPOD. These strikes concentrated on destroying rocket launch sites and the supporting infrastructure, and claimed the elimination of 980 launchers (IDF, 2012a, 2012b).

Gaza militants responded by firing 1506 rockets at Israel during the 8-day operation, including 316 on 15 November alone (IDF, 2012a). Most were directed at towns near Gaza, though 10 longerranged rockets were fired towards Tel Aviv and Jerusalem (ISA, 2013a). According to the IDF, 152 of the rockets misfired or landed within Gaza, while 875 landed in open areas within Israel; these caused no 
losses (IDF, 2012a). It seems that the rockets were mostly fired individually or in small groups, though one report mentions a salvo of 16 rockets (Economist, 2012).

This was Iron Dome's first large battle; Rafael (2014) shows videos of the system in action. Israel had 4 batteries spread across its south, and during OPOD added another near its capital (AFP, 2012). The IDF claims to have intercepted 421 rockets, leaving only 58 to hit urban areas. These hits killed 5 Israelis, wounded 240 more (IDF, 2012a), and caused property damage that triggered 3165 insurance claims (Pedatzur, 2013). Assuming average property damage of $\$ 190 \mathrm{~K}$ per hit (Kober, 2013), this implies $58 \times 190=\$ 11.02$ million in total property damage.

\subsection{Fitting the Model}

The OPOD data can be used to calibrate the model from Section 3 to represent Iron Dome's performance. To start with, consider the losses inflicted by the rockets that hit. If Israel suffered 245 casualties from 58 rocket hits, then the average was $245 / 58=4.224$ casualties per hit. These casualties would likely have been much higher without Israel's civil defenses. Zucker and Kaplan (2014) estimated that rocket attack casualties in the town of Sderot between 2001 and 2010 would have been 3 to 9 times higher in the absence of such passive defenses. This suggests that a target hardening value of at least $h=$ 3 would be appropriate here, in which case the average nominal loss against an unprepared target would have been $v=3 \times 4.224=12.672$ casualties per hit. Property damage can be measured by insurance claims, which averaged $v=3165 / 58=54.569$ claims per hit; or financially at $\$ 190 \mathrm{~K}$ per hit. Measures such as sirens and shelters presumably had little impact on property losses, so set $h=1$ for those.

The interception capacity of an Iron Dome battery is secret (Shapir 2013b). It is known that flight times for Qassam rockets range from 10 to 45 seconds (Dullum, 2009; Mizroch, 2012), and apparently the battery crew has only 3 to 5 seconds to make each interception decision (CBS, 2013). Dividing the median flight time of 27.5 seconds by the median decision time of 4 seconds provides a very rough estimate for the capacity, i.e. $n=27.5 / 4=6.875 \approx 7$ interceptions per salvo.

Regarding the rockets themselves, $1506-152-875=479$ successfully launched towards urban areas in Israel, making the proportion accurate $p_{m}=479 / 1506=31.81 \%$. The IDF claimed to have intercepted 421 of these rockets, for an interception success rate of $p_{n}=421 / 479=87.89 \%$, assuming that all rockets were fired at areas protected by Iron Dome. Since the batteries sometimes fired Tamirs in pairs, this rate reflects the average per volley, not per individual Tamir interceptor missile.

However, there was subsequently some debate regarding the actual interception rate. For one thing, there were apparently 109 police reports of rockets hitting urban areas during OPOD (Pedatzur, 2013). This suggests a lower interception rate of $(479-109) / 479=77.24 \%$. Assuming the total losses remain as before, the larger number of hits necessarily implies smaller losses per hit: $245 / 109=2.248$ casualties, $3165 / 109=29.037$ claims, and $11020 / 109=\$ 101.1 \mathrm{~K}$ damage.

Some critics later suggested that Iron Dome's true success rate was even lower: $30-40 \%, 5-10 \%$, or just 0\% (Broad, 2013; Pedatzur, 2013). They argued that although the Tamirs were exploding in the sky, it was not clear that they were disabling the rocket warheads. If explosion fragments damaged only the rocket body, or missed it completely, then the rocket would continue along its trajectory to the target. Other writers, however, have supported the IDF's claims (Rubin, 2013; Shapir, 2013a).

Suppose that the interception rate was only $35 \%$. This would imply $0.35 \times 479=168$ effective interceptions and $479-168=311$ hits. This would in turn give new losses per hit of 245/311=0.7878 casualties, $3165 / 311=10.177$ claims, and $11020 / 311=\$ 35.4 \mathrm{~K}$ damage. (If there were actually zero interceptions, then the casualties per hit would have been just $245 / 479=0.5115$.) 


\subsection{Relative Contributions to Loss Avoidance}

Israel's losses during OPOD could have been much worse. They were reduced not only by rocket interceptions, but also by civil defenses, preemptive destruction of rockets in Gaza, and the inaccuracy of the rockets themselves. The model provides a way to estimate these reductions.

Zucker and Kaplan (2014) concluded that Israel's civil defenses (target hardening) reduce rocketrelated casualties by at least a factor of 3 . This suggests that OPOD casualties would consequently have been at least $245 \times 3=735$, or 490 higher, if Israel had lacked these passive defenses.

The inaccuracy of the militants' rockets had a similar impact. If $100 \%$ of the rockets had headed towards urban targets, instead of just $31.81 \%$, then casualties and damage would have more than tripled. Rocket inaccuracy thus saved Israel about 525 casualties and 6785 damage claims worth $\$ 23.6$ million.

The IDF reported destroying 980 rocket launchers during OPOD. If this means 980 rockets were thereby destroyed or prevented from being produced, then those preemptive strikes saved Israel about 160 casualties and 2061 damage claims worth $\$ 7.2$ million. (The disruptions to the militants' infrastructure may have produced further savings.)

The benefits from rocket interceptions clearly depend on the success rate. If Iron Dome succeeded $87.89 \%$ of the time, then it saved Israel 1778 casualties and 22970 claims worth $\$ 80.0$ million.

The calculations above are for individual components of Israel's defenses; they estimate the change if one component had been absent. But Section 3 previously noted that increases in interception capacity and decreases in the missile stockpile supplement each other. So what would have been the impact of IDF preemptive strikes on Gaza if Iron Dome had not existed? This was the IDF's predicament prior to 2011; if they didn't destroy the rockets on the ground in Gaza, they could only watch as they landed in Israel. Assuming an interception rate of $87.89 \%$, then without Iron Dome the 980 destructions would have preempted 1317 Israeli casualties. That is, preemptive strikes were 1317/160 = 8.23 times less valuable because of the system. Thus Iron Dome not only gave Israel's political leaders an excuse for not invading Gaza (Shapir, 2013b), it actually made such an invasion less worthwhile.

These casualty avoidance estimates are summarized in the first column of numbers in Table 3. The table's other columns show the corresponding estimates using 3 other potential interception rates. The benefits of target hardening, rocket inaccuracy, and preemptive strikes are the same in all 4 cases. By contrast, the casualties avoided due to Iron Dome depend heavily on its interception success rate; the benefit naturally decreases as the rate decreases. Perhaps less obviously, the same is true for the value of preemptive strikes if Iron Dome were removed. For example, if the true interception rate was only 35\%, then preemptive strikes were only 1.53 times less valuable with the system than without it, and the disincentive for a land invasion of Gaza would have been correspondingly reduced.

\section{Further Modeling and Analysis}

\subsection{Counter-Battery Fire}

Red's objective is to damage Blue's targets, but it may sometimes be worthwhile to fire missiles at the interception system first. If the system can be disabled, then more of the remaining missiles subsequently will reach their targets. (This assumes that the system stays disabled during all remaining attacks.) Of course, such an attack might miss, especially if the interception system is smaller and harder to hit than a regular target. There is also a potential trade-off relating to the interception success rate. If 
the rate is high, then it will be very valuable to disable the system but also difficult to penetrate its defenses to hit it; if the rate is low, then hitting it will be easier but less valuable.

Let $p_{c}$ represent the proportion accurate for Red missiles used in counter-battery fire, $c$ the salvo size fired for this purpose, and $q_{c}$ the resulting proportion of such attempts that disable the system. The loss that Red will inflict with its remaining $A-c$ missiles can be calculated by Equation 2, adjusted to reflect whether or not the system has been knocked out. Red should fire at the interception system only if that increases the losses inflicted; that is, if $\left(q_{c}\right) \operatorname{Loss}_{\text {Out, } A-c}+\left(1-q_{c}\right) \operatorname{Loss}_{A-c}>\operatorname{Loss}_{A}$, where Loss $_{\text {Out, A-c }}=$ $m p_{m}(A-c) v /(h m)$. If Red will be firing $c=1$ missile at a time at the system ("shoot-look-shoot"), then this inequality can be simplified to one of the following, depending on whether Red will subsequently fire small or large salvos at Blue targets; see the appendix for the derivations.

$$
\begin{array}{ll}
p_{c}>1 /\left\{p_{n}(A-1)\right\} & \text { if } m \leq n / p_{m} \\
p_{c}>\left(m p_{m}-n p_{n}\right) /\left\{n p_{n}\left(1-p_{n}\right)(A-1)\right\} & \text { if } m>n / p_{m}
\end{array}
$$

Equation 3 shows that if subsequent salvos will be small, then Red should be more inclined to fire at the system if its chance of hitting it is high, it has many missiles, and/or the interception rate is high.

Equation 4 shows that if subsequent salvos will be large, Red again should be more inclined to attack the system when its chance of hitting it is high or when many missiles are available. In addition, it also should attack when its missile accuracy is low, or its effective salvo size is only slightly greater than the effective interception capacity. With respect to interception success, the right hand side of the expression is decreasing in $p_{n}$ for $p_{n}<0.5$ but might become increasing thereafter, especially with very large salvos. Roughly speaking, Red becomes more likely to shoot at the system as it improves from bad to fair to good, but less likely if it further improves from good to great.

Consider the Iron Dome case with $p_{n}=87.89 \%$. If the militants' attacks were evenly spread across the area covered by the 4 main batteries, then each battery would have faced $A=(1506-10) / 4=$ 374 rockets. Assuming the militants were restricted to small salvos, they should have fired their first rocket at the battery only if their chance of hitting it was at least $p_{c}>1 /(0.8789(374-1))=0.305 \%$. If the rocket missed the battery, they could have continued firing at it, but the threshold would have increased each time; e.g., with only 100 rockets left, they would have needed $p_{c}>1 /(0.8789(100-1))=1.149 \%$.

Alternatively, suppose that the militants had been able to fire large salvos of 30 rockets at Israel. Then they would have benefited from firing at the battery only if the chance of hitting was at least $p_{c}>$ $(30 \times 0.3181-7 \times 0.8789) /\{(374-1) 0.8789(1-0.8789) 7\}=1.22 \%$. This number is higher than the $0.305 \%$ from the small salvo case: because large salvos are less impeded by interceptions, disabling the system becomes less worthwhile. If instead the interception rate was $77.24 \%$, then the militants would have needed $p_{c}>0.89 \%$. If the interception rate was $35 \%$, then $p_{c}>1.18 \%$ would have been needed.

To put these numbers in perspective, consider that these unguided rockets are very inaccurate, with circular error probable (CEP) ratings of around 1000 meters (FAS, 1999; Rubin, 2013). Also, each one has a lethal radius of only about 5 meters (Zucker and Kaplan, 2014). Thus a rocket's chance of disabling either the battery's control module or radar module might be just $0.0034 \%$, based on calculations using a Rayleigh distribution (see, e.g., Eckler and Burr, 1972: 27). This suggests that the militants would need rockets at least $0.305 / 0.0034 \approx 90$ times more accurate for counterbattery fire. 


\subsection{Discouraging Large Salvos}

Since losses are increasing in salvo size for $m>n / p_{m}$, Red clearly should prefer to concentrate its missiles into large salvos. If there is some physical limit on its salvo size, such as the number of launchers, then Red should fire salvos equal to that limit.

However, there may be other factors that discourage large salvos. If Red is an insurgent organization, it may lack good communications with its personnel, making it difficult to coordinate multiple launch sites. As well, Blue may be working to detect and destroy the missiles prior to launch. Since larger salvos would require more time, space, and/or personnel to prepare, they presumably would face increasing risks of detection by informants or aerial patrols. (Preparation time was a key variable in the counterterrorism model of Kaplan, 2010.)

To model this issue, let increasing function $g(m)$ represent the proportion of salvos destroyed by Blue before launch, where the derivative $g^{\prime}(m)>0$. This changes the loss equation as follows.

$$
\text { Loss }=\left\{m p_{m}\left(1-p_{n}\right)+\left[m p_{m} p_{n}-n p_{n}\right]^{+}\right\}(1-g(m))(A v) /(h m)
$$

For small salvos, $\partial \operatorname{Loss} / \partial m=-g^{\prime}(m) p_{m}\left(1-p_{n}\right) A v / h$ is negative, confirming that losses decrease with salvo size. So if Red must use small salvos, it should fire individual missiles. For large salvos, $\partial$ Loss $/ \partial m=\left\{-g^{\prime}(m)\left(p_{m}-n p_{n} / m\right)+(1-g(m))\left(n / m^{2}\right)\right\} A v / h$, and its sign will depend on $g(m)$.

For example, suppose that the fraction of missiles preemptively destroyed by the IDF in Gaza is $g(m)=k(m-1)$, and that the interception rate is $87.89 \%$. With a $k=1 \%$ chance of discovery per added rocket, the optimal salvo has 44 rockets. With $k=2 \%$, this drops to 31 rockets. With $k=3 \%$, it is best to fire individual rockets, as the risk of discovery then outweighs the benefits of large salvos.

\subsection{Imperfect Missile Classification}

If Blue can perfectly distinguish between inaccurate and accurate missiles, it only needs to intercept the latter. But if this distinction is imperfect, then some inaccurate missiles may be incorrectly treated as accurate. Such "false positives" might occur, for example, if Blue defines a safety margin around the target. Missiles slightly outside the target area would then be selected for interception.

To model this, suppose that proportion $\left(1-p_{m}\right)$ of Red's attack is actually inaccurate, but Blue classifies only $\left(1-p_{m}-p_{f p}\right)$ as inaccurate. Proportion $p_{f p}$ represents false positives: missiles that won't cause damage, but that Blue will attempt to intercept. In effect, these act as decoys. Assuming that Blue intercepts both types of missiles in proportion to their numbers, then fraction $\left(p_{m} /\left(p_{m}+p_{f p}\right)\right)$ of the interceptions will be directed against accurate missiles and the remainder against false positives.

(Note that Iron Dome's ability to correctly discriminate between accurate and inaccurate rockets is very important: it permits the system to focus on just the $31.81 \%$ of rockets that would otherwise hit towns. Otherwise, the batteries would need to engage $100 \%$ of the rockets, effectively making $p_{f p}=$ $68.19 \%$. This would roughly triple their consumption of expensive Tamir interceptors. It would also drop each battery's effective interception capacity from $n / p_{m} \approx 22$ down to just $n=7$ rockets per salvo, making it more susceptible to being overloaded by large salvos.)

Alternatively, Blue might incorrectly classify some accurate missiles as being inaccurate. These "false negatives" would go unchallenged and subsequently hit the target. Suppose that proportion $p_{m}$ is actually accurate, but Blue classifies only $\left(p_{m}-p_{f n}\right)$ as accurate, and so ignores proportion $p_{f n}$. 
These features change Equation 1 as follows; the other equations change in a similar manner.

$$
\text { Hits / salvo }=m p_{m}\left(1-p_{n}\right)+m p_{f n} p_{n}+\left(p_{m} /\left(p_{m}+p_{f p}\right)\right)\left[m p_{m} p_{n}+m p_{f p}-n p_{n}\right]^{+}
$$

This incidentally provides a way to partially reconcile the conflicting estimates of Iron Dome's interception rate during OPOD. For example, suppose that the interception rate was 35\%, the IDF counted 479 rockets heading towards urban areas, and 109 rockets hit. The first two numbers imply that only 479 x $0.35=168$ rockets were effectively intercepted; but if only 109 of the rest hit urban targets, then 202 were not intercepted and yet did not hit targets. Perhaps only 109/(1-0.35) $\approx 167$ rockets were actually headed towards urban areas; and of these, $167 \times 0.35 \approx 58$ were intercepted. There would have been $(479-167) /(1-0.35) \approx 312$ false positives headed for rural areas but treated as threats; of these, $312 \times 0.35=110$ would have been intercepted. This gives a real missile accuracy rate of $p_{m}=167 / 1506=$ $11.09 \%$, along with a false positive rate of $p_{f p}=312 / 1506=20.72 \%$, where $20.72+11.09=31.81$.

Conversely, suppose instead that the interception rate during OPOD was $87.89 \%$, and that 421 of 479 rockets were effectively intercepted, leaving 58 to strike their targets; and yet 109 hits were recorded. Perhaps the remaining 51 hits came from other rockets that were also accurate but not part of the 479 identified as such. In this case the rockets would have had a true accuracy rate of $p_{m}=(479+51) / 1506=$ $35.19 \%$, along with a false negative rate of $p_{f n}=35.19 \%-31.81 \%=3.38 \%$.

These calculations are not intended to suggest that false positives and negatives were the main reasons for differences in reported interception rates; the "fog of war" admits many other possibilities. But they do show that imperfect missile classification would have contributed to those differences.

\section{A Stochastic Approach}

So far this paper has viewed the missile accuracy rate and interception success rate as constant proportions. This section instead treats them as probabilities and develops a stochastic version of the model, similar to how Armstrong (2005) extended Hughes' (1995) model of naval missile combat.

\subsection{Stochastic Model}

Let Bernoulli random variable $X_{i}$ represent missile $i$ : it equals 1 with probability $p_{m}$ to indicate the missile is accurate, and 0 otherwise. Likewise let $Y_{j}$ represent the success of interception attempt $j$, taking a value of 1 with probability $p_{n}$ if successful, and 0 otherwise. The total numbers of accurate missiles $M$ and successful interceptions $N$ per salvo therefore are also random variables, and can be written as summations; their difference gives the number of hits per salvo as follows.

$$
\begin{gathered}
\text { Accurate missiles / salvo } M=\sum_{i=1}^{m} X_{i} \quad \text { Interceptions / salvo } N=\sum_{j=1}^{\min \{M, n\}} Y_{j} \\
\text { Hits / salvo }=M-N=\sum_{i=1}^{m} X_{i}-\sum_{j=1}^{\min \{M, n\}} Y_{j}
\end{gathered}
$$

Equation 6 simplifies when $m \leq n$, so that every missile faces an interception attempt. It becomes a single summation, with a mean that matches the deterministic model.

$$
E[\text { Hits / salvo }]=E\left[\sum_{i=1}^{m} X_{i}\left(1-Y_{i}\right)\right]=m p_{m}\left(1-p_{n}\right) \quad \text { when } m \leq n
$$


Equation 6 also has a simple approximation when salvos are large enough that every available interceptor has an accurate missile to challenge; i.e., where almost always $M \geq n$. It becomes a pair of independent sums, with a mean difference that also matches the corresponding deterministic case.

$$
E[\text { Hits / salvo }] \approx E\left[\sum_{i=1}^{m} X_{i}-\sum_{j=1}^{n} Y_{j}\right]=m p_{m}-n p_{n} \quad \text { when } M \geq n
$$

Between the extremes of very small and very large salvos, Equation 1 will underestimate the mean number of hits as calculated by Equation 6, especially when the number of accurate missiles is close to the interception capacity, i.e., $m p_{m} \approx n$. This is because the actual number of accurate missiles sometimes will exceed that capacity by chance, even though their average number is less.

In modeling this feature, this paper will follow the practice of some existing studies by assuming that the missile and interception variables are all (approximately) statistically independent from each other. For example, Wilkening (1999) described several reasons why BMD interceptions could be either independent or dependent, but assumed independence in all of his calculations. Similarly, Armstrong (2005) assumed independence when modeling naval missile battles. Armstrong (2011) later showed that the resulting model tolerates small amounts of statistical dependence. In particular, the model's estimate of mean losses remains reasonable even with correlation of +0.4 between missiles.

Given this approximation, reconsider the numerical example from Section 3. Each Red missile has probability $p_{m}=3 / 4$ of being accurate, and Blue can make up to $n=6$ interceptions per salvo, each with probability $p_{n}=2 / 3$ of success. If Red fires $m=4$ missiles, the mean number of hits calculated using Equation 6 and binomial distributions will be 1, as in the deterministic model. If $m=12$, then the mean hits will be 5.012, almost matching the 5 from the deterministic model. If however Red fires 8 missiles, then the mean hits will be 2.312 , rather than the 2 from the deterministic model.

To adjust for this factor, start by taking expectations of Equation 6 .

$$
E[\text { Hits / salvo }]=E\left[\sum_{i=1}^{m} X_{i}-\sum_{j=1}^{\min \{M, n\}} Y_{j}\right]=m p_{m}-E[\min \{M, n\}] p_{n}
$$

The term $E[\min \{M, n\}]$ can be closely approximated via the same technique Armstrong (2005, 2014) used for stochastic salvo models of naval missile combat; see the appendix for details. Armstrong (2011) showed that this approximation is very good across a wide range of parameter values.

$$
E[\min \{M, n\}] \approx m p_{m} F(n)+n[1-F(n)]-m p_{m}\left(1-p_{m}\right) f(n)
$$

Here, $f(n)$ represents the probability density function and $F(n)$ the cumulative distribution function for a normal approximation to the binomial distribution of $M$; it has mean $m p_{m}$ and variance $m p_{m}\left(1-p_{m}\right)$, and is evaluated at the interception capacity $n$. This leads to expressions for the mean number of hits per salvo and the mean total losses. When $M$ is either very large or very small relative to $n$, these expressions approach their deterministic equivalents, as then $f(n) \approx 0$ and either $F(n) \approx 0$ or $F(n) \approx 1$.

$$
\begin{aligned}
& E[\text { Hits/salvo }]=m p_{m}\left(1-p_{n}\right)+\left(m p_{m} p_{n}-n p_{n}\right)[1-F(n)]+m p_{m}\left(1-p_{m}\right) p_{n} f(n) \\
& E[\text { Loss }]=(A / m)\left\{m p_{m}\left(1-p_{n}\right)+\left(m p_{m} p_{n}-n p_{n}\right)[1-F(n)]+m p_{m}\left(1-p_{m}\right) p_{n} f(n)\right\}(v / h)
\end{aligned}
$$

Continuing with the previous numerical example, Table 2 shows how the hits estimated by Equations 6 and 7 compare. The approximation seems quite reasonable. 
Figure 1 compares the deterministic and stochastic models in the OPOD case. It displays the total rocket hits estimated by each model across a range of salvo sizes, given $p_{n}=87.89 \%$ and a fixed total of 1506 rockets. The dashed line represents the deterministic model, while the solid line represents the stochastic model. As expected, the outputs are indistinguishable for very small and very large salvos. For example, both models indicate that salvos of 9 rockets at a time would have caused 58 hits total (the actual OPOD figure), while salvos of 49 rockets would have caused 290 ( 5 times more). In between, the stochastic model's estimates are higher than the deterministic ones; the largest difference occurs around $m$ $\approx n / p_{m}$. This is the point where the deterministic model shows an abrupt increase in losses; the stochastic model produces a more gradual transition along an s-shaped curve. The incremental loss increase (curve steepness) in both models is also greatest near $m \approx n / p_{m}$, and gradually diminishes thereafter.

\subsection{Salvo Sizes versus Iron Dome}

The calculations in this paper have assumed that the majority of rocket attacks during OPOD were made with small salvos ( $m \leq 22$ rockets), so that hits occurred only after the corresponding interception attempts had failed. This seems like a reasonable assumption given the available data. However, if the salvos had been consistently larger, Israel's losses could have been much higher.

Figure 2 uses the stochastic model to estimate mean casualties with 3 interception rates for a range of salvo sizes. All of the curves are s-shaped, with their steepest slopes around the small-to-largesalvo transition point $m=n / p_{m}$. In a sense the interception capacity $n$ and the missile accuracy rate $p_{m}$ determine the figure's "horizontal scale". For example, the plots assume $n=7$ interception attempts per salvo; if its actual value is lower or higher, then the transition point will shift to the left or the right, respectively. However, the overall shapes of each curve will remain much the same.

Figure 2 also illustrates some other properties that were derived earlier. For example, the overall steepness of the curves is greatly influenced by the interception rate $p_{n}$. If the true interception rate was high, then few rockets leaked through the defenses, and each one was credited with many casualties. Thus each rocket that exceeds the interception capacity makes a large incremental addition to the total hits, and each hit adds many casualties. Conversely, a low interception rate means that many rockets were already leaking through the defenses, each causing relatively few casualties. In this case, extra rockets make only small additions to the total hits, and each hit adds only slightly to the total casualties.

Figure 3 refines this comparison by displaying the mean number of rocket hits for the same interception rates and salvo sizes. If the interception rate is high, then the total hits are low for small salvos, but increase quickly once the interception capacity is exceeded. By contrast, if the interception rate is low, then the hits are moderately high even for small salvos, and increase only slightly as salvo sizes increase. In each case, the mean number of hits asymptotically approaches the 479 that would occur if there were no interceptions.

Figure 4 shows the mean number of rocket hits for different salvo sizes as well, but it compares 4 different rocket accuracy rates. The lowest curve represents the number of hits for the OPOD accuracy rate of $31.81 \%$, while the other curves show the impact of improving (multiplying) this rate by a factor of 1.5, 2.0, and 2.5. Not surprisingly, increased rocket accuracy yields more hits. More subtly, it also shifts the small-to-large-salvo transition point to the left, showing that the Iron Dome batteries would become more easily overloaded if the militants were to improve their rocket accuracy. 


\section{Discussion}

\subsection{Comments Regarding Iron Dome}

Missile defense is expensive. For Iron Dome, the initial cost to construct each battery has been estimated at \$50 million (BBC, 2012; Mizroch, 2012), giving a total of \$200 million for the 4 main batteries active during OPOD. Estimates for Tamir interceptor missiles range from $\$ 40 \mathrm{~K}$ to $\$ 75 \mathrm{~K}$ each, with $\$ 50 \mathrm{~K}$ being common (CBS, 2013; AFP, 2012; BBC, 2012; Mizroch, 2012), and in some cases during OPOD several interceptors were fired as a volley against a single rocket. Altogether during OPOD the batteries expended $\$ 25$ to $\$ 30$ million worth of Tamirs (NBC, 2012). This suggests roughly 500 to 600 interceptors were fired, or an average of 1.04 to 1.25 Tamirs per rocket engaged. By contrast, if Iron Dome successfully intercepted 421 rockets as claimed, then this expenditure saved Israel from about 1778 casualties and $\$ 80$ million worth of property damage.

The effectiveness of interception systems depends heavily on the salvo sizes they face. Iron Dome seems to provide credible protection against low-volume threats, such as sporadic attacks from dissident factions during relatively quiet years like 2013. It also protects against moderate-volume attacks that are relatively uncoordinated, such as during OPOD. In this regard, it can complicate the militants' planning: on the one hand, small salvos can now be countered by interception; on the other hand, large salvos may be more risky to carry out.

However, if in the future the militants increase their salvo sizes even slightly beyond Iron Dome's interception capacity, the resulting losses could increase quickly. This nonlinear or "fragile" behavior suggests that Israel must not rely on interceptions alone. It must work to minimize the salvo sizes and rocket accuracy of the militants, e.g., by detecting potential rocket build-ups and interdicting arms shipments. As well, Iron Dome would provide little benefit against high-volume threats, such as regulararmy multiple rocket launcher vehicles that can each fire 40-rocket barrages (FAS, 1999).

\subsection{Research Extensions and Limitations}

This paper developed its model to study rocket attacks against Israel, but it also could be applied to situations elsewhere in the Middle East, as well as locations such as Korea. A renewed conflict between North and South Korea would likely include a variety of missile fire (Kim, 2013). The model could represent potential North Korean attacks with KN-2 Toksa missiles against nearby Seoul. Longerrange attacks by Scud missiles would better fit the theater BMD model of Brown et al (2005).

The model herein might also be useful alongside existing salvo models (e.g., Armstrong, 2005) for representing naval missile warfare where only one interception attempt per missile is possible. This may include attacks by very fast anti-ship missiles, such as the P-700 Granite supersonic cruise missile or the DF-21 Dong Feng ballistic missile. It could also include conventional missiles fired at close range, as might occur during battles in the littorals. For example, coastal patrol boats might surprise an approaching amphibious group by hiding among the mundane masses of coastal freighters and fishing trawlers. Research along these lines could build on the scenarios examined numerically in graduate theses such as that of Tiah (2007).

One limitation of this research is that its empirical data for OPOD is far from perfect. This is not surprising, given that they come from an unresolved military conflict where both sides focus on fighting their battles, not on taking scientific measurements. Furthermore, the participants have obvious motives to keep certain information secret, and perhaps to distort whatever they make public. Thus all of the numerical details here need to be viewed with a degree of caution. Conversely, one of the benefits of 
developing this model is to allow analysts with access to classified data, or with different assessments of the true military situation, to easily rerun the calculations.

\section{Appendix}

\section{A1. Basic Model Properties for Section 3}

The first derivatives of the Equation 2 loss function are shown below.

$$
\begin{aligned}
& \partial \operatorname{Loss} / \partial A=\left\{m p_{m}\left(1-p_{n}\right)+\left[m p_{m} p_{n}-n p_{n}\right]^{+}\right\}(v) /(h m)>0 \\
& \partial \operatorname{Loss} / \partial v=\left\{m p_{m}\left(1-p_{n}\right)+\left[m p_{m} p_{n}-n p_{n}\right]^{+}\right\}(A) /(h m)>0 \\
& \partial L o s s / \partial h=\left\{m p_{m}\left(1-p_{n}\right)+\left[m p_{m} p_{n}-n p_{n}\right]^{+}\right\}(-v A) /\left(h^{2}\right)<0
\end{aligned}
$$

For small salvos only:

$$
\begin{aligned}
& \partial \operatorname{Loss} / \partial p_{n}=-p_{m} v A / h<0 \quad \partial \operatorname{Loss} / \partial n=0 \\
& \partial \operatorname{Loss} / \partial p_{m}=\left(1-p_{m}\right) v A / h>0 \quad \partial \operatorname{Loss} / \partial m=0
\end{aligned}
$$

For large salvos only:

$$
\begin{aligned}
& \partial \operatorname{Loss} / \partial p_{n}=-(n v A) /(h m)<0 \quad \partial \operatorname{Loss} / \partial n=-\left(p_{n} v A\right) /(h m)<0 \\
& \partial \text { Loss } / \partial p_{m}=v A / h>0 \quad \partial \operatorname{Loss} / \partial m=p_{n}\left(n / m^{2}\right)(A v / h)>0
\end{aligned}
$$

The complementary and supplementary relationships follow from the second partial derivatives. For example, with large salvos $\partial$ Loss $/ \partial p_{n} \partial n=-(v A) /(h m)<0$ and $\partial \operatorname{Loss} / \partial p_{n} \partial m=\left(n / m^{2}\right)(A v / h)>0$.

\section{A2. Counterbattery Fire Analysis for Subsection 5.1}

Red should attack the interception system if $\left(q_{c}\right) \operatorname{Loss}_{\text {Out, A-c }}+\left(1-q_{c}\right) \operatorname{Loss}_{A-c}>\operatorname{Loss}_{A}$. That is,

$$
\begin{gathered}
\left(q_{c}\right) m p_{m}(A-c) v /(h m)+\left(1-q_{c}\right)\left\{m p_{m}\left(1-p_{n}\right)+\left[m p_{m} p_{n}-n p_{n}\right]^{+}\right\}(A-c) v /(h m) \\
>\left\{m p_{m}\left(1-p_{n}\right)+\left[m p_{m} p_{n}-n p_{n}\right]^{+}\right\} A v /(h m)
\end{gathered}
$$

If $c=1$ missile at a time, then $q_{c}=p_{c}\left(1-p_{n}\right)$ and this simplifies to

$$
\begin{gathered}
p_{c}\left(1-p_{n}\right) m p_{m}(A-1)+\left\{1-p_{c}\left(1-p_{n}\right)\right\}\left\{m p_{m}\left(1-p_{n}\right)+\left[m p_{m} p_{n}-n p_{n}\right]^{+}\right\}(A-1) \\
>\left\{m p_{m}\left(1-p_{n}\right)+\left[m p_{m} p_{n}-n p_{n}\right]^{+}\right\} A
\end{gathered}
$$

This further simplifies when $m \leq n / p_{m}$.

$$
\begin{aligned}
& p_{c}\left(1-p_{n}\right) m p_{m}(A-1)+\left\{1-p_{c}\left(1-p_{n}\right)\right\}\left\{m p_{m}\left(1-p_{n}\right)\right\}(A-1)>m p_{m}\left(1-p_{n}\right) A \\
& p_{c}(A-1)+\left\{1-p_{c}\left(1-p_{n}\right)\right\}(A-1)>A \\
& \left(1+p_{c} p_{n}\right)(A-1)>A
\end{aligned}
$$

Alternatively, it simplifies as follows when $m>n / p_{m}$.

$$
\begin{aligned}
& p_{c}\left(1-p_{n}\right) m p_{m}(A-1)+\left\{1-p_{c}\left(1-p_{n}\right)\right\}\left(m p_{m}-n p_{n}\right)(A-1)>\left(m p_{m}-n p_{n}\right) A \\
& p_{c}\left(1-p_{n}\right) m p_{m}(A-1)+\left(m p_{m}-n p_{n}\right)(A-1)-p_{c}\left(1-p_{n}\right)\left(m p_{m}-n p_{n}\right)(A-1)>\left(m p_{m}-n p_{n}\right) A \\
& p_{c}\left(1-p_{n}\right) n p_{n}(A-1)>m p_{m}-n p_{n} \\
& p_{c}>\left(m p_{m}-n p_{n}\right) /\left\{n p_{n}\left(1-p_{n}\right)(A-1)\right\}
\end{aligned}
$$


To see the behavior with respect to interception rates, take the derivative of the right hand side.

$$
\begin{gathered}
\partial / \partial p_{n} \text { RHS }=\left[-n\left\{n p_{n}\left(1-p_{n}\right)(A-1)\right\}-\left(m p_{m}-n p_{n}\right)\left\{n\left(1-2 p_{n}\right)(A-1)\right\}\right] /\left\{n p_{n}\left(1-p_{n}\right)(A-1)\right\}^{2} \\
=-\left[n p_{n}\left(1-p_{n}\right)+\left(m p_{m}-n p_{n}\right)\left(1-2 p_{n}\right)\right] /\left\{n p_{n}^{2}\left(1-p_{n}\right)^{2}(A-1)\right\}
\end{gathered}
$$

With large salvos, $\left(m p_{m}-n p_{n}\right)>0$; so this is negative when $p_{n}<0.5$, but may be positive when $p_{n}>0.5$.

\section{A3. Stochastic Model Derivations for Section 6}

Since the $X_{i}$ are iid, $M$ follows a binomial distribution. To derive an approximation for $E[\min \{M, n\}]$, replace the summation by integration and approximate the distribution of $M$ with a normal distribution with mean $\mu=m p_{m}$, variance $\sigma^{2}=m p_{m}\left(1-p_{m}\right)$, probability density function $f()$, and cumulative distribution function $F()$, where $F(m)=1, F(0)=0$, and $f(m)=f(0)=0$.

$$
E[\min \{M, n\}]=\int_{0}^{n} l f(l) d l+\int_{n}^{m} n f(l) d l
$$

The following is a known result for normal distributions (see, e.g., the appendix of Armstrong, 2005).

$$
\int_{T 1}^{T 2} t f(t) d t=\mu\left[F\left(T_{2}\right)-F\left(T_{1}\right)\right]-\sigma^{2}\left[f\left(T_{2}\right)-f\left(T_{1}\right)\right]
$$

Combine these two expressions and simplify as follows.

$$
\begin{gathered}
E[\min \{M, n\}]=\int_{0}^{n} l f(l) d l+\int_{n}^{m} n f(l) d l \approx \mu[F(n)-F(0)]-\sigma^{2}[f(n)-f(0)]+n[F(m)-F(n)] \\
=\mu[F(n)-0]-\sigma^{2}[f(n)-0]+n[1-F(n)]=m p_{m} F(n)+n[1-F(n)]-m p_{m}\left(1-p_{m}\right) f(n) \\
E[N]=E[\min \{M, n\}] E[Y]=m p_{m} F(n) p_{n}+n[1-F(n)] p_{n}-m p_{m}\left(1-p_{m}\right) f(n) p_{n} \\
\begin{array}{c}
E[\text { Hits/salvo }]=E[M]-E[N]=m p_{m}-m p_{m} F(n) p_{n}-n[1-F(n)] p_{n}+m p_{m}\left(1-p_{m}\right) f(n) p_{n} \\
=m p_{m}\left(1-p_{n}\right)+m p_{m} p_{n}[1-F(n)]-n[1-F(n)] p_{n}+m p_{m}\left(1-p_{m}\right) f(n) p_{n}
\end{array}
\end{gathered}
$$

\section{Acknowledgements}

Thanks are due to Edward Kaplan and Evanna Mills for pointing-out several good references, and to the referees and editors for their suggestions. The author conducted this research during his stay as the Fulbright Visiting Research Chair in War and Peace Studies at Norwich University in Vermont.

\section{References}

AFP. 2012. Israel's Iron Dome plays growing role in Gaza conflict. Agence France-Presse, 16 Nov. http://www.google.com/hostednews/afp/article/ALeqM5iZV78IKMHWZyqLrBYuEoor0MPZ9Q?do cId=CNG.2cf3bc7be53e2f556cc0a63105c9224a.6f1

Arce D.G., Kovenock D., Roberson B. 2012. Weakest-link attacker-defender games with multiple attack technologies. Naval Research Logistics 59 \#6, 457-469.

Armstrong M.J. 2014. The salvo combat model with a sequential exchange of fire. Journal of the Operational Research Society. doi:10.1057/jors.2013.115.

Armstrong M.J. 2011. A verification study of the stochastic salvo combat model. Annals of Operations Research 186 \#1, 23-38.

Armstrong M.J. 2007. Effective attacks in the salvo combat model: salvo sizes and quantities of targets. Naval Research Logistics 54, \#1, 66-77. 
Armstrong M.J. 2005. A stochastic salvo model for naval surface combat. Operations Research 53, \#5, 830-841.

Atkinson M.P., Wein L.M. 2008. Spatial queueing analysis of an interdiction system to protect cities from a nuclear terrorist attack. Operations Research 56 \#1, 247-254.

BBC. 2012. Israel's Iron Dome missile shield. British Broadcasting Corporation, 18 Nov. http://www.bbc.com/news/world-middle-east-20385306

Broad W.J. 2013. Weapons experts raise doubts about Israel's antimissile system. New York Times, 20 Mar. http://www.nytimes.com/2013/03/21/world/middleeast/israels-iron-dome-system-is-at-centerof-debate.html?pagewanted=all\&_r=0

Brown G., Carlyle M., Diehl D, Kline J., Wood K. 2005. A two-sided optimization for theater ballistic missile defense. Operations Research 53 \#5, 745-763.

Burr S.A., Falk J.E., Karr A.F. 1985. Integer Prim-Read solutions to a class of target defense problems. Operations Research 33 \#4, 726-745.

CBS. 2013. Will Israel's "Iron Dome" help bring peace? Columbia Broadcasting System, 60 Minutes, 17 Feb. https://www.youtube.com/watch?v=KacOhvGeVA0

Dullum O. 2009. The Rocket Artillery Reference Book. FFI Report 2009/00179, Norwegian Defense Research Establishment, Oslo. http://rapporter.ffi.no/rapporter/2009/00179.pdf

Eckler A.R., Burr S.S. 1972. Mathematical Models of Target Coverage and Missile Allocation. Military Operations Research Society, Alexandria.

Economist. 2012. Dome Warfare. The Economist, 24 Nov. http://www.economist.com/news/middle-eastand-africa/21567115-israelis-can-fend-most-missiles-some-will-still-get

Enders W., Sandler T. 2012. The Political Economy of Terrorism. Cambridge University Press, Cambridge.

FAS. 1999. 9K51 BM-21 Grad. Federation of American Scientists. Washington. http://www.fas.org/man/dod-101/sys/land/row/bm-21.htm

Harel A., Cohen G. 2014. U.S. pledges more money for Iron Dome - but IDF lacks trained personnel. Haaretz, 13 Mar. http://www.haaretz.com/news/diplomacy-defense/.premium-1.579513

Hughes W.P. 1995. A salvo model of warships in missile combat used to evaluate their staying power. Naval Research Logistics 42 \#2, 267-289.

IDF. 2012b. Operation Pillar of Defense: Summary of Events. Israeli Defense Forces, 22 Nov. http://www.idfblog.com/2012/11/22/operation-pillar-of-defense-summary-of-events/

IDF. 2012a. Ceasefire agreement comes into effect. Israeli Defense Forces, 21 Nov. http://www.idf.il/1153-17717-EN/Dover.aspx

ISA. 2013b. 2013 Annual Summary - Terrorism and CT Activity Data and Trends. Israel Security Agency. http://www.shabak.gov.il/English/EnTerrorData/Reports/Pages/2013AnnualSummary.aspx

ISA. 2013a. Reviews - Operation Pillar of Defense. Israel Security Agency. http://www.shabak.gov.il/English/EnTerrorData/Reviews/Pages/OperationPillarofDefense.aspx

ISA. 2012. 2012 Annual Summary - Terrorism and CT Activity Data and Trends. Israel Security Agency. http://www.shabak.gov.il/English/EnTerrorData/Reviews/Pages/2012AnnualSummary.aspx

Kaplan E.H. 2010. Terror queues. Operations Research 58 \#4 Part 1, 773-784.

Kaplan E.H., Kress M., Szechtman R. 2010. Confronting entrenched insurgents, Operations Research 58, 329-341.

Kim D. 2013. North Korea's Nuclear and Ballistic Missile Programs. Center for Arms Control and Nonproliferation, Washington.

http://armscontrolcenter.org/issues/northkorea/articles/fact_sheet_north_korea_nuclear_and_missile programs/

Kober A. 2013. Iron Dome: Has the euphoria been justified? Perspectives Paper No. 199, 25 Feb. BeginSadat Center for Strategic Studies, Bar-Ilan University, Ramat Gan. http://besacenter.org/perspectives-papers/iron-dome-has-the-euphoria-been-justified/

Kress M. 2005. The effect of crowd density on the expected number of casualties in a suicide attack. Naval Research Logistics 52 \#1, 22-29. 
Matlin S. 1970. A review of the literature on the missile-allocation problem. Operations Research 18 \#2, 334-373.

Mizroch A. 2012. Israel's rocket-hunting ace got his start playing Warcraft. Wired, 6 Apr. http://www.wired.com/dangerroom/2012/04/israel-rocket-warcraft/all/1

NBC. 2012. Israel's Iron Dome shield against Gaza rockets cost up to $\$ 30$ million. National Broadcasting System News, 22 Nov. http://worldnews.nbcnews.com/news/2012/11/22/15363974-israels-irondome-shield-against-gaza-rockets-cost-up-to-30-million?lite

Paraszczuk J. 2011. Petition rejected to deploy Iron Dome near border towns. Jerusalem Post, 9 Aug. http://www.jpost.com/Defense/Petition-rejected-to-deploy-Iron-Dome-near-border-towns

Pedatzur R. 2013. How many rockets has Iron Dome really intercepted? Haaretz, 9 Mar. http://www.haaretz.com/opinion/how-many-rockets-has-iron-dome-really-intercepted.premium1.508277

Rafael. 2010. Iron Dome. Rafael Advanced Defense Systems Ltd. http://www.rafael.co.il/Marketing/1861530-en/Marketing.aspx

Rafael. 2014. Iron Dome Interception. Video montage, posted 29 Jan. https://www.youtube.com/watch?v=J3qaGic-qGw

Rubin U. 2013. Is the iron dome effective? Jerusalem Post, 4 Apr. http://www.jpost.com/Opinion/Op-EdContributors/Is-the-Iron-Dome-effective-308711

Selinger M. 2013. The road to iron dome. Aerospace America 51 \#4, Apr, 26-31.

Shapir Y. 2013b. Lessons from the Iron Dome. Military and Strategic Affairs 5 \#1, 81-94. http://www.inss.org.il/index.aspx?id=4538\&articleid=2660

Shapir Y. 2013a. How many rockets did Iron Dome shoot down? INSS Insight No. 414, 21 Mar. Institute for National Security Studies, Tel Aviv. http://www.inss.org.il/index.aspx?id=4538\&articleid=2635

Soland R.M. 1987. Optimal terminal defense tactics when several sequential engagements are possible. Operations Research 35 \#4, 537-542.

Tiah Y.M. 2007. An Analysis of Small Navy Tactics Using a Modified Hughes' Salvo Model. Master's thesis, Operations Research Department, U.S. Naval Postgraduate School, Monterey.

Wilkening D.A. 2000. A simple model for calculating ballistic missile defense effectiveness. Science \& Global Security 8, 183-215.

Zucker L., Kaplan E.H. 2014. Mass casualty potential of Qassam rockets. Studies in Conflict and Terrorism 37, 258-266.

Michael J. Armstrong is an associate professor who teaches courses on quality improvement and operations management at Brock University. His research analyzes tactical missile warfare and defenses, at sea and on land. He won a Chancellor's Chair for Teaching Excellence award in 2012, and a Fulbright Scholar award in 2013. 
Table 1. Notation for the basic model and its enhancements.

\begin{tabular}{ll}
\hline Symbol & Description \\
\hline$A$ & Total available stockpile of attacker's missiles \\
$m$ & Number of missiles fired per salvo \\
$p_{m}$ & Proportion of missiles that are accurate \\
$n$ & Number of interception attempts per salvo \\
$p_{n}$ & Proportion of interceptions that are successful \\
$v$ & Damage value per hit on non-hardened targets \\
$h$ & Damage mitigation due to target hardening \\
\hline$c$ & Number of missiles fired counter-battery \\
$p_{c}$ & Proportion of missiles accurate against the system \\
$q_{c}$ & Resulting chance of hitting the interception system \\
$g()$ & Proportion of salvos destroyed prior to launch \\
$k$ & Chance of prior destruction, per missile per salvo \\
$p_{f n}$ & Proportion of missiles that are false negatives \\
$p_{f p}$ & Proportion of missiles that are false positives \\
\hline$M$ & Total number of accurate missiles \\
$N$ & Total number of successful interceptions \\
$X_{i}$ & Accuracy of missile $j: 1=$ accurate, $0=$ not \\
$Y_{j}$ & Success of interception $l: 1=$ successful, $0=$ not \\
$F()$ & Cumulative distribution function for $M$ \\
$f()$ & Probability density function for $M$ \\
\hline
\end{tabular}

Table 2. Hits per salvo from the deterministic model, the stochastic model, and direct numerical calculation, for an example with $n=6, p_{m}=2 / 3$ and $p_{n}=3 / 4$.

\begin{tabular}{lccccccccc}
\hline Missiles $m$ & 4 & 5 & 6 & 7 & 8 & 9 & 10 & 11 & 12 \\
\hline I. Deterministic & 1.000 & 1.250 & 1.500 & 1.750 & 2.000 & 2.750 & 3.500 & 4.250 & 5.000 \\
II. Stochastic & 1.000 & 1.252 & 1.525 & 1.868 & 2.326 & 2.902 & 3.563 & 4.274 & 5.008 \\
III. Numerical & 1.000 & 1.250 & 1.500 & 1.839 & 2.312 & 2.901 & 3.568 & 4.279 & 5.012 \\
Difference II - III & 0.000 & +0.002 & +0.025 & +0.029 & +0.014 & +0.001 & -0.005 & -0.005 & -0.004 \\
\hline
\end{tabular}

Table 3. OPOD casualties avoided for various cause factors and interception rates.

\begin{tabular}{lrrrr}
\hline Interception success $p_{n}$ & $87.89 \%$ & $77.24 \%$ & $35.00 \%$ & $0.00 \%$ \\
\hline Target hardening & 490 & 490 & 490 & 490 \\
Rocket inaccuracy & 525 & 525 & 525 & 525 \\
Interceptions & 1778 & 831 & 132 & 0 \\
Preemptive strikes & 160 & 160 & 160 & 160 \\
Preemption, no interception & 1317 & 701 & 245 & 160 \\
Relative preemption value & 8.23 & 4.38 & 1.53 & 1.00 \\
\hline
\end{tabular}


Figure 1. Estimated hits for the stochastic and deterministic models, with accuracy rate $31.81 \%$ and interception rate $87.89 \%$.

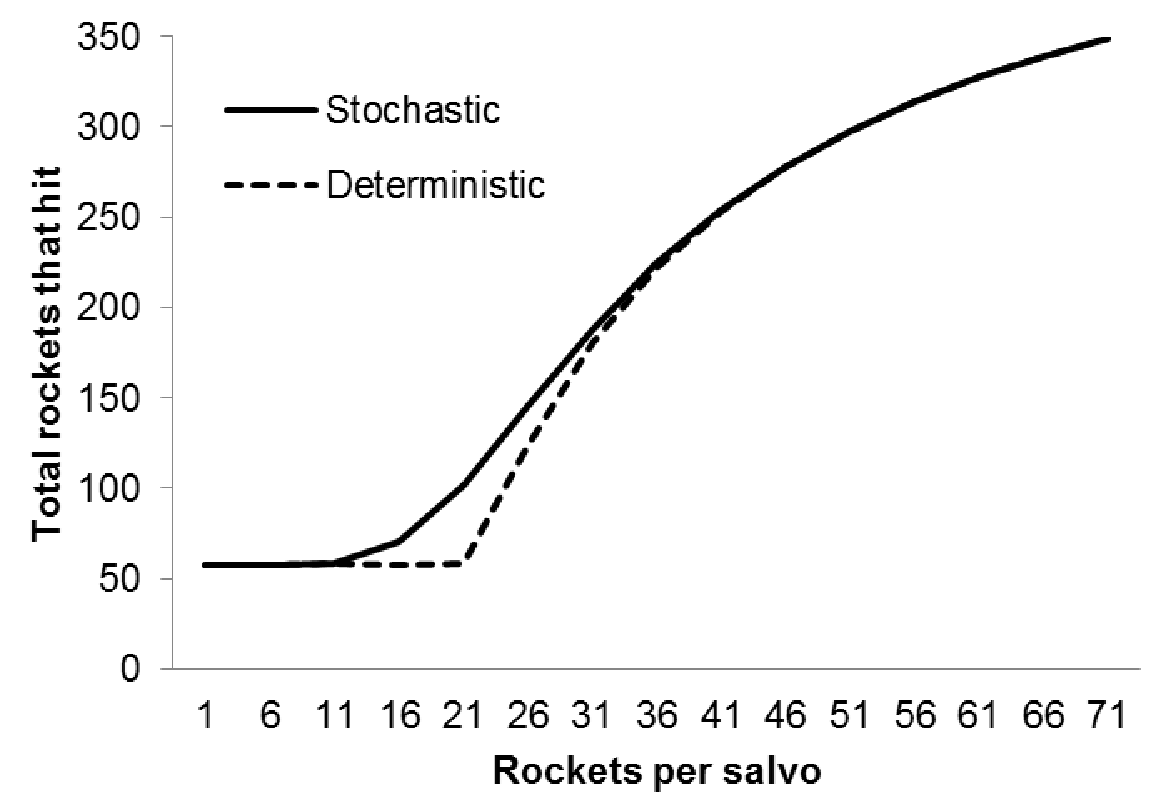

Figure 2. Mean casualties for 3 interception rates, using accuracy rate $31.81 \%$.

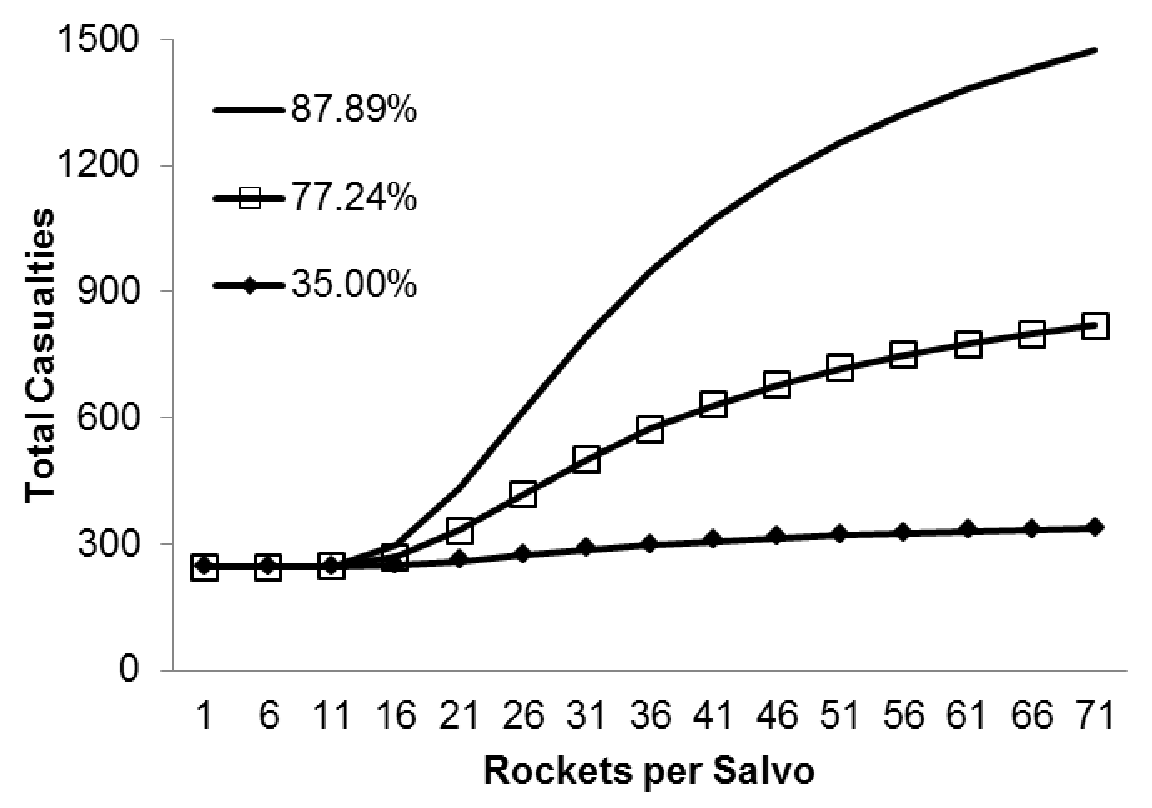


Figure 3. Mean hits for 3 interception rates, using accuracy rate $31.81 \%$.

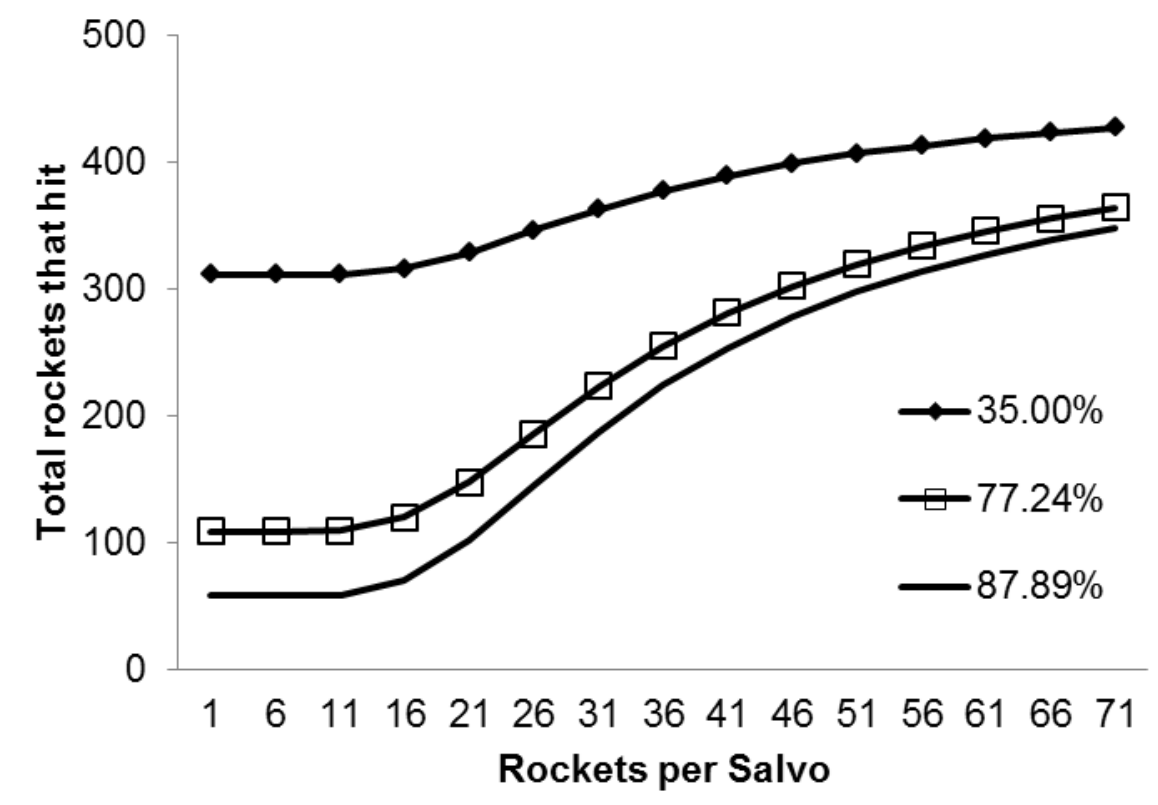

Figure 4. Mean hits for 4 missile accuracy rates, using interception rate $87.89 \%$.

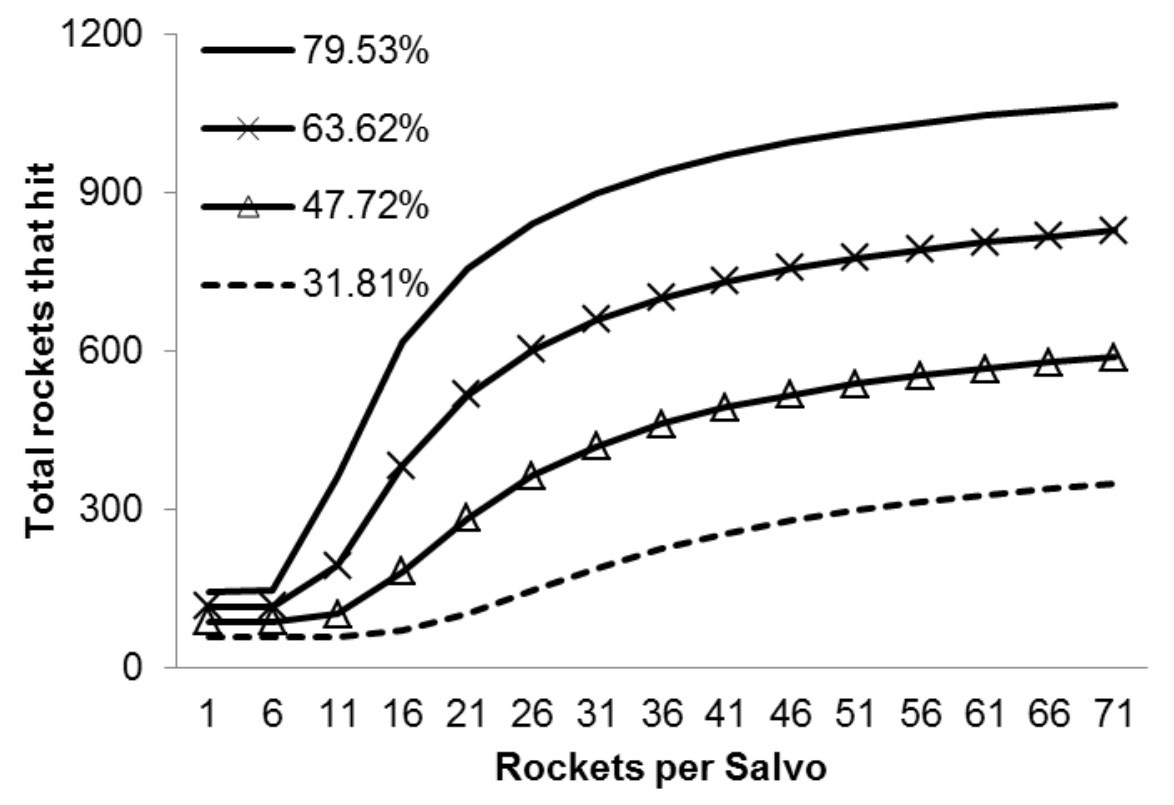

